\title{
Cutting concentration prediction in horizontal and deviated wells using artificial intelligence techniques
}

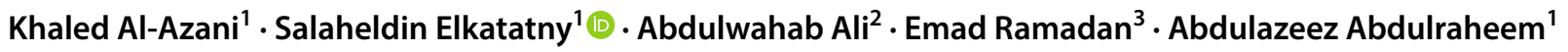

Received: 16 October 2018 / Accepted: 20 April 2019 / Published online: 27 April 2019

(c) The Author(s) 2019

\begin{abstract}
Improper hole cleaning or drilled-cutting transportation impacts drilling operations. To illustrate, inefficient cleaning of the wellbore can lead to many drilling problems such as low drilling rate (i.e. low ROP), early bit wear and, in the severe cases, a complete loss of the well due to stuck pipe. To understand efficiency in cutting transport in drilling and to provide solutions for the problem, many studies have been conducted. In all cases, they provide empirical models based on experimental data. In this study, different artificial intelligence (AI) techniques are employed to estimate the concentration of cuttings present in the wellbore. The purpose of this study is to indirectly measure the hole-cleaning efficiency in order to predict the cutting concentration from drilling parameters using artificial intelligence techniques. The study is based on 116 experimental data records from the studies. Two AI techniques were selected, namely artificial neural network (ANN) and support vector machine (SVM), to estimate the cutting concentration in the wellbore. The input parameters comprise mud density and mud rheological properties (yield point and plastic viscosity) in addition to drilling parameters including the hole inclination angle, pipe eccentricity (i.e. location of the drill pipe from the axis of the well), the rate of penetration (ROP), flow rate (GPM), drill pipe rotary speed (RPM) and temperature. The results obtained show the ability of the two employed techniques to accurately predict the cutting concentration in the wellbore with average absolute errors (AAE) less than 5\% and correlation coefficients (R) higher than 0.9. Comparison of these results with a literature model showed that the AI techniques provide better predictions of cutting concentration and higher accuracy than that model. Applying the developed AI technique will help the drilling engineers to assess the hole cleaning in a real time.
\end{abstract}

Keywords Cutting transportation $\cdot$ Hole cleaning $\cdot$ Artificial intelligence $\cdot$ Horizontal wells

Salaheldin Elkatatny

elkatatny@kfupm.edu.sa

Khaled Al-Azani

g201080760@kfupm.edu.sa

Abdulwahab Ali

awali@kfupm.edu.sa

Emad Ramadan

eramadan@kfupm.edu.sa

Abdulazeez Abdulraheem

aazeez@kfupm.edu.sa

1 Department of Petroleum Engineering King, Fahd

University of Petroleum \& Minerals, 5049, Dhahran 31261,

Saudi Arabia

2 Center for Integrative Petroleum Research (CIPR), Fahd University of Petroleum \& Minerals, 5049, Dhahran 31261, Saudi Arabia

3 Information \& Computer Science Department, King Fahd University of Petroleum \& Minerals, 5049, Dhahran 31261, Saudi Arabia

\begin{tabular}{ll}
\multicolumn{2}{l}{ List of symbols } \\
AAE & Average absolute error \\
ANN & Artificial neural networks \\
BPNN & Back-propagation neural network \\
$\mathrm{C}_{\mathrm{C}}$ & Cutting concentration $(\%)$ \\
FL & Fuzzy logic \\
$\mathrm{Q}$ & Flow rate $(\mathrm{GPM})$ \\
$\mathrm{R}$ & Correlation coefficient \\
$\mathrm{R}^{2}$ & Coefficient of determination \\
RBFN & Radial basis functional network \\
ROP & Rate of penetration $(\mathrm{ft} / \mathrm{hr})$ \\
$\mathrm{RPM}$ & Pipe rotation $(\mathrm{rpm})$ \\
$\mathrm{SVM}$ & Support vector machine \\
$\mathrm{T}$ & Temperature $\left({ }^{\circ} \mathrm{F}\right)$ \\
YP & Yield point $\left(\mathrm{lb} / 100 \mathrm{ft}{ }^{2}\right)$ \\
$\theta$ & Inclination angle $(\mathrm{degree})$ \\
$\mu_{\mathrm{p}}$ & Plastic viscosity $(\mathrm{cP})$ \\
$\rho$ & Mud density $(\mathrm{ppg})$
\end{tabular}

List of symbols

AAE Average absolute error

ANN Artificial neural networks

BPNN Back-propagation neural network

$\mathrm{C}_{\mathrm{C}} \quad$ Cutting concentration (\%)

FL Fuzzy logic

Q Flow rate (GPM)

$\mathrm{R} \quad$ Correlation coefficient

$\mathrm{R}^{2} \quad$ Coefficient of determination

RBFN Radial basis functional network

ROP Rate of penetration (ft/hr)

RPM Pipe rotation (rpm)

SVM Support vector machine

$\mathrm{T} \quad$ Temperature $\left({ }^{\circ} \mathrm{F}\right)$

YP Yield point $\left(\mathrm{lb} / 100 \mathrm{ft}^{2}\right)$

$\theta \quad$ Inclination angle (degree)

$\rho \quad$ Mud density (ppg) 


\section{Introduction}

Oil and gas drilling operations include the process that is aimed at penetrating the earth surface to a subsurface hydrocarbon reservoir through a bore hole called wellbore or well. During this process, small rock fragments are produced and more of these fragments are generated as the hole gets deeper and deeper. Therefore, removing the rock cutting from the wellbore, drilling fluids, also referred to as drilling mud, is used. Drilling fluid basically is a mixture of a continuous phase (either oil or water), weighting agents (e.g. barite) and some viscosifying agents (e.g. bentonite). The ability of the drilling fluid to lift the drilled cuttings off the wellbore is governed by several factors. These factors are related to both the properties of the mud itself such as the mud density (mud weight), mud rheology and to some drilling parameters such as the hole inclination angle, drill pipe eccentricity (i.e. location of the drill pipe from the axis of the well), rate of penetration (ROP), pipe rotary speed (RPM) and more. Inefficient removal of the drilled cuttings may lead to many problems. These problems are costly and may include low ROP, early bit wear and, in some severe cases, a complete loss of the well due to stuck pipe. Therefore, it is very important to put the hole-cleaning efficiency into consideration during the drilling process.

Many studies have been conducted to understand the factors that affect the hole-cleaning efficiency. The first study on cutting transport was by Pigott (1941) in which the parameters affecting the carrying capacity of mud were identified. The first study trying to estimate the least possible annular velocity necessary to remove the cuttings from the hole was conducted by Williams and Bruce (Williams and Bruce 1951). After that, a series of experimental studies were conducted trying to understand and identify the parameters that influence the hole-cleaning efficiency. Other studies were conducted trying to model or correlate the cutting transport during drilling operations. Some studies used computer built-in models and simulators to simulate the drilling operations and monitor the cutting transport. Finally, Nazari et al. (2010) presented a comprehensive review of cutting transport.

\section{Applications of artificial intelligence in petroleum industry}

Artificial intelligence (AI) techniques have been widely used in the oil and gas industry. AI techniques have been applied in reservoir characterization, drilling and production processes. For example, a model to identify the flow regimes in the wellbores was developed by El-Sayed (Osman 2004) using the artificial neural networks. Abdulraheem et al. (2007) used the fuzzy logic (FL) for estimating the Middle East permeability. The AI was also used by Al-Shammari (2011) to predict the pressure's drop in the bottom-hole and tubing head in two-phase flow systems in an oil-producing well. In 2012, Al-Marhoun et al. (2012) presented an AI model for predicting crude oil viscosity. Alakbari et al. (2016) also used different artificial intelligence techniques for the prediction of bubble-point pressure $\left(\mathrm{P}_{\mathrm{bp}}\right)$.

Elkatatny et al. (2016) used the ANN technique for real-time prediction of drilling fluid rheological properties. Elkatatny (2017a) also used the same technique for drill-in fluids, which is used to drill the reservoir section. It has been also demonstrated that, based on drilling fluid properties and the drilling mechanical properties, the ANN technique can be used to determine the ROP with a high accuracy (Elkatatny 2017b). Elkatatny (2017b), Elkatatny et al. (2017, 2018a) developed a new empirical correlation based on ANN for predicting porosity and permeability based on well log data and showed that the black box of the ANN can be changed to a white box by developing this empirical correlation. A new correlation for permeability determination from well logs has been also developed based on the same technique, Moussa et al. (2018). Abdulhameed et al. (Mahmoud et al. 2017) predicted the total organic carbon based on conventional well log data using ANN. The ANN was also used to predict the bubble-point pressure $\left(\mathrm{P}_{\mathrm{bp}^{-}}\right)$and oil formation volume factor $\left(\mathrm{B}_{\mathrm{o}^{-}}\right)$with a high accuracy based on surface measurements (Elkatatny and Mahmoud 2018a, b). In reservoir geomechanics, ANN has also been applied successfully to estimate the geomechanical parameters based on well logs data. For example, Elkatatny et al. (2018b) implemented ANN with high accuracy to predict the static Young's modulus based on well log data. Static Poisson's ratio was predicted for the first time using ANN by Elkatatny (2018). Finally, Elkatatny et al. (2018c) developed a mathematical model for the prediction of the compressional and shear sonic times using ANN from log data including gamma ray, bulk density and neutron porosity.

Nevertheless, few researchers have used the AI techniques for studying the hole cleaning during drilling operations. The first AI study on hole cleaning was done by Ozbayoglu et al. (2002) in which they used the feed-forward neural networks with back-propagation learning algorithm (BPNN) to investigate the cutting bed height in horizontal and highangle wells. In their study, they used Reynolds number $\left(\mathrm{N}_{\mathrm{Re}}\right)$, Froude number $\left(\mathrm{N}_{\mathrm{Fr}}\right)$ and cutting concentration $\left(\mathrm{C}_{\mathrm{C}}\right)$ as the input parameters, whereas the cutting bed height was the output parameters. These dimensionless numbers are functions of inclination angle, feed cutting concentration, 
fluid density, fluid viscosity, average velocity, pipes dimensions and the wellbore.

Rooki et al. (2014) and Rooki and Rakhshkhorshid (2017) used the BPNN and the radial basis neural networks (RBFN) for hole-cleaning prediction in foam drilling. In both studies, the authors used experimental data containing the foam quality, foam velocity, eccentricity, pipe rotational speed (RPM) and subsurface conditions (e.g. pressure and temperature) as the input parameters, whereas the cutting concentration was the target (output) parameter.

Al-Azani et al. (2018) concluded that SVM can be used to predict the cutting concentration in the wellbore with high accuracy. The purpose of this study is to develop artificial neural networks (ANN) model to indirectly predict the holecleaning efficiency by estimating the cutting concentration in the wellbore from other drilling parameters and compare the results with the SVM which was developed by Al-Azani et al. (2018). In addition, the results from these techniques (ANN, SVM) will be compared to a correlation presented in the literature.

\section{The parameters affecting hole-cleaning efficiency}

The following subsections show how the different parameters affect the cutting transport efficiency. These observations were taken from the literature in which experimental studies were conducted to understand these parameters and their influence on the hole-cleaning efficiency.

\section{Effect of wellbore inclination}

Tomren et al. (1986) in their experimental work, and depending on several conditions, showed that there is no significant difference in the cutting concentration when the tests were conducted at $10^{\circ}$ of inclination than those conducted in vertical holes. They also showed that at wellbore inclinations, between $10^{\circ}$ and $30^{\circ}$, the formation of cutting bed is induced mainly at low flow rates. The tendency for the cuttings bed to slide downwards was observed at inclinations of $40^{\circ}$ and $50^{\circ}$. Finally, at higher angles, the build-up of cuttings on one side of the annulus was observed due to the drill pipe rotation which caused the tangential "sway" of the cuttings bed. Moreover, various degrees of cuttings build-up are resulted at higher angles of inclinations. This leads to the need for higher flow rates than those recommended for safely cleaning the vertical holes. Finally, the cuttings bed is more likely to slide downwards for 35-50 degrees of inclination (Tomren et al. 1986).

\section{Effects of pipe/hole eccentricity}

It was observed that in vertical holes, the behaviour of the cuttings was almost the same for different eccentricities.
However, for inclined drill section, it was observed that cutting build-up was least when the inner pipe was co-cantered (i.e. zero eccentricity) with the outer pipe (Tomren et al. 1986).

\section{Effect of mud rheology and density}

Experimental investigations on the effect of the mud rheology on the hole cleaning by Hussaini and Azar (1983), Okranji and Azar (1986) showed that the carrying capacity of the mud increases by increasing the ratio between the yield point (YP) and the plastic viscosity $\left(\mu_{\mathrm{p}}\right)$. They also showed that the lower the viscosity of the mud, the more effective hole cleaning is. Moreover, the lower the mud viscosity is, the higher the tendency of the cuttings to roll, Ford et al. (1990).

\section{Effect of flow rate}

The works of Tomren et al. (1986), Li and Walker (1999), Cho et al. (2001) and Ravi and Hemphill (2006) showed that the cuttings beds height decreases by increasing the flow rate and, hence, the annular velocity.

\section{Effect of pipe rotation (rpm) and rate of penetration (ROP)}

It has been shown that the rotation speed (RPM) is more effective in high-angle wells than vertical wells. The hydraulic requirements for effective cleaning also increase with increasing the ROP (Tomren et al. 1986) and Sanchez et al. (1999).

\section{Overview of the implemented Al techniques}

\section{Artificial neural networks (ANN)}

The artificial neural network is an information-processing system that tries to mimic the performance characteristics of human nervous system. The system is adapted as a computer model that can develop associations, transformations or mappings between objects or data. ANN is also the most popular AI technique for recognizing patterns of data. Furthermore, any ANN is built-up of basic elements called neurons; that is, the ANN is collection neurons with specifically arranged formations. What is more, correlations that depend on large number of inputs can be found using the ANN. In this technique, set of operations in which the outputs and the inputs are combined are made by the essential parts of the network, which are the neurons. Nonlinear equations are also used to obtain the results for prediction problems.

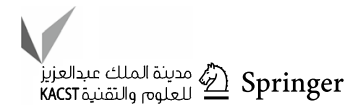




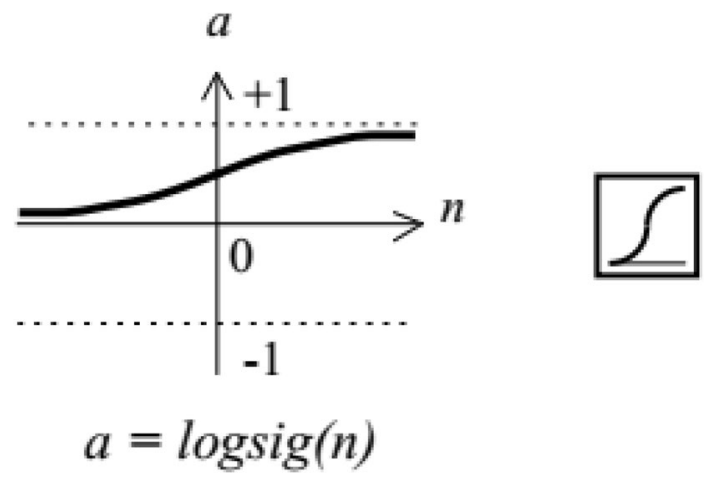

$\log \operatorname{sig}(n)=\frac{1}{1+e^{-n}}$

Fig. 1 Plot of the log-sigmoid transfer function (Demuth and Beale 2002)

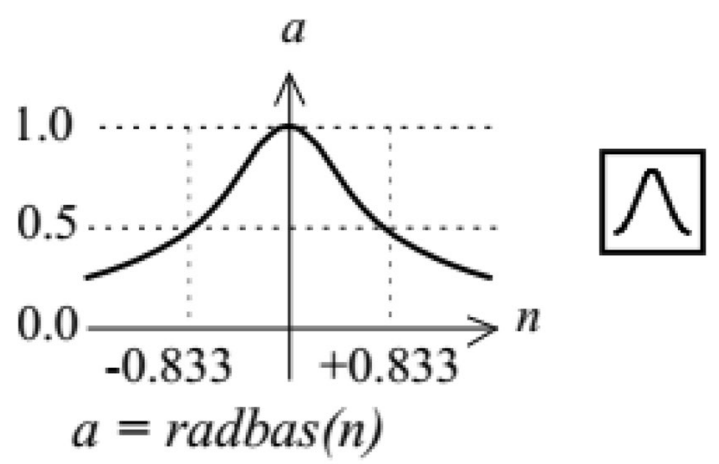

$$
\operatorname{radbas}(n)=e^{-n^{2}}
$$

Fig. 2 Plot of the radial basis transfer function (Demuth and Beale 2002)

There are different ANN models. These include the feedforward neural networks with the back-propagation (BPNN) learning algorithm and the radial basis functional networks (RBFN) which are implemented in this work. In the BPNN, the input parameters and the corresponding output parameters are used to train the network so that a function can be approximated, and a specific output is associated with a specific input(s) or a classification is made as assigned by the user. In this technique, and depending on the type of the problem, several activation functions are used for solving the problem. The log-sigmoid activation function is used in this study. This function is shown in Fig. 1. In contrast, the RBFN uses the radial basis transfer function shown in Fig. 2. This type of network is useful in approximating functions and making classifications.
In this technique, more neurons are required than those in the BPNN approximation (Demuth and Beale 2002).

\section{Support vector machine (SVM)}

The support vector machines were first added to the computer learning community in the mid-1990s, Cortes and Vapnik (1995). SVM is most commonly used to solve very large classification problems. It has been extended to be able to solve nonlinear regression problems, in which they show excellent performance, Zhao et al. (2010). In support vector machine, the basic idea of solving the problems is mapping the data into high dimension feature space. Then, the relationship between the input and the output in a new space is found. The data are classified by the construction of a hyper-plane in which the data are separated into two categories. The models of SVM are related to the neural networks in which the SVM uses the sigmoidal kernel function which is equivalent to a two-layer perceptron neural network.

\section{Data description and analysis}

Yu et al. (2007) conducted an experimental study of hole cleaning at the University of Tulsa. They conducted their experiment under simulated downhole conditions. The total number of tests were 116 in which pipe rotation (RMP), mud density $(\rho)$, mud rheological properties (yield point (YP) and the plastic viscosity $\left.\left(\mu_{\mathrm{p}}\right)\right)$, pipe eccentricity $(\varepsilon)$, temperature $(\mathrm{T})$, flow rate $(\mathrm{Q})$, rate of penetration $(\mathrm{ROP})$ and inclination angle $(\theta)$ were varied to investigate their effect on cutting concentration $\left(\mathrm{C}_{\mathrm{C}}\right)$. The test matrix of the experiment is illustrated in Table 1. Their data are used in this work.

For sensitivity analyses of the relationship between the input parameters and the output parameter, the correlations coefficients $(\mathrm{R})$ between the independent (input parameters) and the dependent (output) parameter are shown in Table 2 and Fig. 3, and these data were obtained using the EXCEL program by selecting the data analysis function. As shown in Fig. 3, Q, RPM, $\rho$, T, YP, $\mu_{\mathrm{p}}, \theta, \varepsilon$ and ROP, respectively, have the more negative effect on the $\mathrm{C}_{\mathrm{C}}$. This negative correlation agrees with what have been previously presented regarding the parameters affecting the hole-cleaning efficiency.

The data were divided into two parts in which $70 \%$ of the data was used for training and the remaining $30 \%$ of the data was used for testing. The selection of training and testing data was done randomly in the MATLAB code during the implementation of the techniques.

For training and testing using the SVM technique, the inputs parameters were normalized in the range $[-1,1]$. For this purpose, the following equation was used (Demuth and Beale 2002):

$$
x_{n}=2 \times \frac{x-x_{\min }}{x_{\max }-x_{\min }}-1
$$



2007)
Table 1 Test matrix (Yu et al.

\begin{tabular}{llll}
\hline Testing parameter & Values & \\
\hline Annular size & $5.76^{\prime \prime}$ casing ID $\times 3.5^{\prime \prime}$ drill string OD & \\
Rotation $(\mathrm{RPM})$ & 0,80 & & \\
Eccentricity, $\varepsilon$ & $0.541^{\prime \prime}, 0.881^{\prime \prime}$ offset & & \\
Mud rheology & Yield point, YP & Plastic viscosity, $\mu_{\mathrm{p}}$ & \\
& $0,20,40\left(\mathrm{lb} / 100 \mathrm{ft}^{2}\right)$ & $1,10,20(\mathrm{cP})$ & \\
Temperature, $\mathrm{T}\left({ }^{\circ} \mathrm{F}\right)$ & $80,120,180$ & & \\
Rate of penetration, ROP $(\mathrm{ft} / \mathrm{hr})$ & $15,20,3040$ & & \\
Flow rate, $\mathrm{Q}(\mathrm{GPM})$ & $75,100,150,200,250$ & & Standard deviation \\
Density, $\rho$ (ppg) & $8.314,8.33,12$ & $10.97 \%$ \\
Inclination angle, $\theta($ degree $)$ & $67,90 \quad$ Average & \\
Cutting concentration, $\mathrm{C}_{\mathrm{C}}(\%)$ & Range & {$[0,41] \quad 11.45 \%$} & \\
\end{tabular}

Table 2 Correlation coefficients between the inputs and the target

\begin{tabular}{ll}
\hline Parameter & $\begin{array}{l}\text { Correlation } \\
\text { coefficient } \\
(\mathrm{R})\end{array}$ \\
\hline$\rho$ & -0.3162 \\
$\mu_{\mathrm{p}}$ & -0.1093 \\
$\mathrm{YP}$ & -0.1104 \\
$\mathrm{~T}$ & -0.1251 \\
$\mathrm{ROP}$ & -0.0189 \\
$\mathrm{RPM}$ & -0.4767 \\
$\mathrm{Q}$ & -0.4793 \\
$\theta$ & -0.1036 \\
$\varepsilon$ & -0.0437 \\
\hline
\end{tabular}

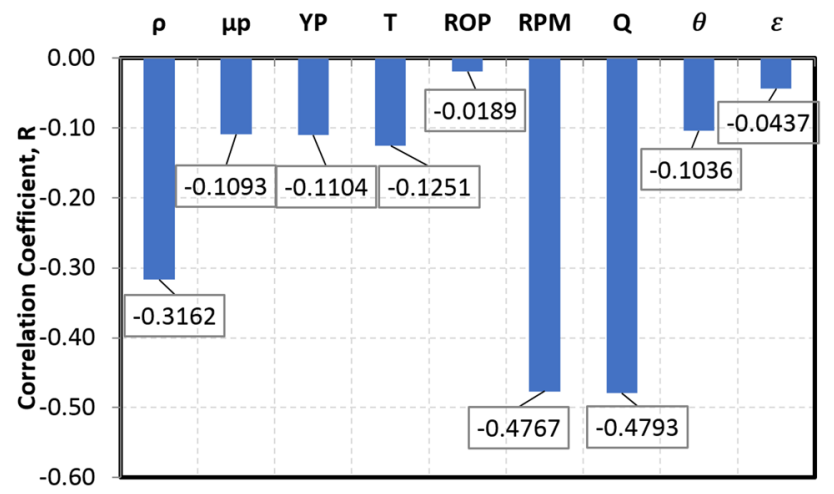

Fig. 3 The correlation coefficient between the input parameters and the cutting concentration

where $x_{n}$ is the normalized parameter, $x$ is the actual parameter, and $x_{\min }$ and $x_{\max }$, respectively, represent the minimum and the maximum values of the actual parameters.

Finally, for performance evaluation, the correlation coefficient $(R)$ and the average absolute error (AAE) are used and they are defined by the following equations, respectively:

$$
\begin{aligned}
& R=\sqrt{1-\frac{\sum_{i}^{N}\left(y_{\text {iact }}-y_{\text {ipred }}\right)^{2}}{\sum_{i}^{N}\left(y_{\text {iact }}\right)^{2}-\frac{\sum_{i}^{N}\left(y_{\text {ipred }}\right)^{2}}{N}}} \\
& A A E=\frac{1}{N} \sum_{i}^{N}\left|y_{\text {iact }}-y_{\text {ipred }}\right|
\end{aligned}
$$

where $y_{\text {iact }}$ represents the measured (actual) value, $y_{\text {ipred }}$ represents the predicted (estimated) value, and $N$ denotes the number of samples. Higher values of $\mathrm{R}$ with lower values of AAE indicate higher accuracy and better performance of prediction.

\section{Cutting concentration estimation using BPNN}

In this technique, a feed-forward neural network with backpropagation (BPNN) learning algorithm was applied. Several trials were applied to perform a sensitivity analysis for the number of the hidden layers, the number of neurons in the hidden layer(s) and the appropriate transfer function. The final network consists of three layers as follows: one input layer with nine input parameters, one hidden layer with nine neurons and the $\log$-sig transfer function and one output layer with one output parameters. Figure 4 shows the ANN topography.

\section{Cutting concentration estimation using RBFN}

In this study, the RBFN algorithm was also used for estimating the cutting concentration. This algorithm is designed using newrbe code in MATLAB $®$. In training the RBFN, the proper value of spread must be determined. Therefore, different values of spread were tested until the minimum AAE 


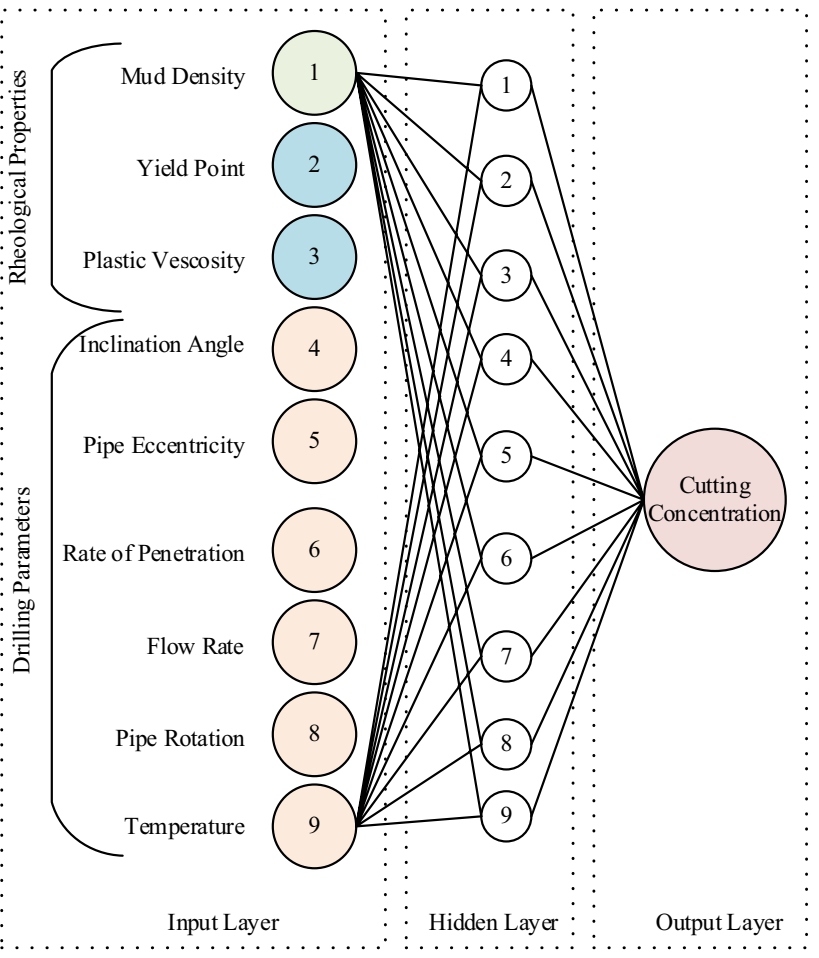

Each neuron in the input layer is connected to every neuron in the hidden layer and each neuron in the hidden layer is connected to the output layer neuron.

Fig. 4 ANN topography

and maximum $\mathrm{R}$ were obtained. Several trials and errors led to the value of 241 for the spread.

\section{Cutting concentration estimation using SVM}

Support vector machine technique was also implemented as a regression tool to predict the cutting concentration from the aforementioned input parameters. For better performance of the tool, a sensitivity analysis of SVM parameters was performed until the minimum AAE and maximum $\mathrm{R}$ were obtained.

\section{Results and discussion}

\section{Results from BPNN model}

The cutting concentration was estimated using the BPNN technique. In this technique, the model was trained and tested, and the best results are outlined and discussed here. Figures 5 and 6 show the plot of the actual (experimental) and predicted cutting concentration versus the test number as obtained from the training and testing stages after implementing the BPNN. Figures 7 and 8 also show the regression plots for both stages between the actual and predicted data. The figures show the closeness of the predicted $C_{C}$ to

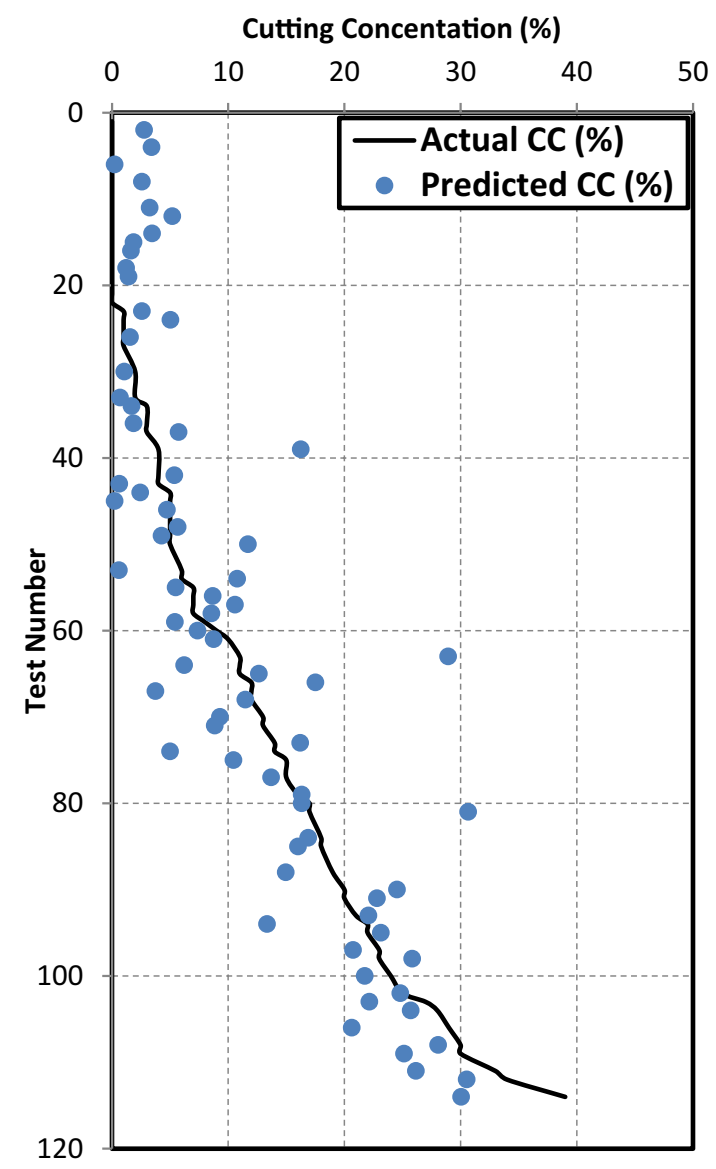

Fig. 5 Actual (experimental) and BPNN-predicted cutting concentration versus test number from network training

the actual $\mathrm{C}_{\mathrm{C}}$. The training correlation coefficient and the average absolute error (AAE) in this stage are 0.9017 and $3.3079 \%$, respectively. The correlation coefficient for the testing stage is 0.8691 with an AAE of $4.5692 \%$. The training and testing results indicate that the model performance is very satisfactory. Table 3 summarizes the results obtained from implementing the BPNN technique for estimating cutting concentration. The overall correlation coefficient is 0.89 with an AAE of $3.686 \%$ which also indicate a satisfactory performance of the model.

\section{Results from RBFN model}

The cutting concentration was estimated using the RBFN technique. In this technique, the model was trained and tested, and the best results are outlined and discussed here. Figures 9 and 10 show the plot of the actual (experimental) and predicted cutting concentration versus the test number as obtained from the training and testing stages after implementing the RBFN. Figures 11 and 12 also show the regression plots for both stages between the actual and predicted data. The figures show the closeness 


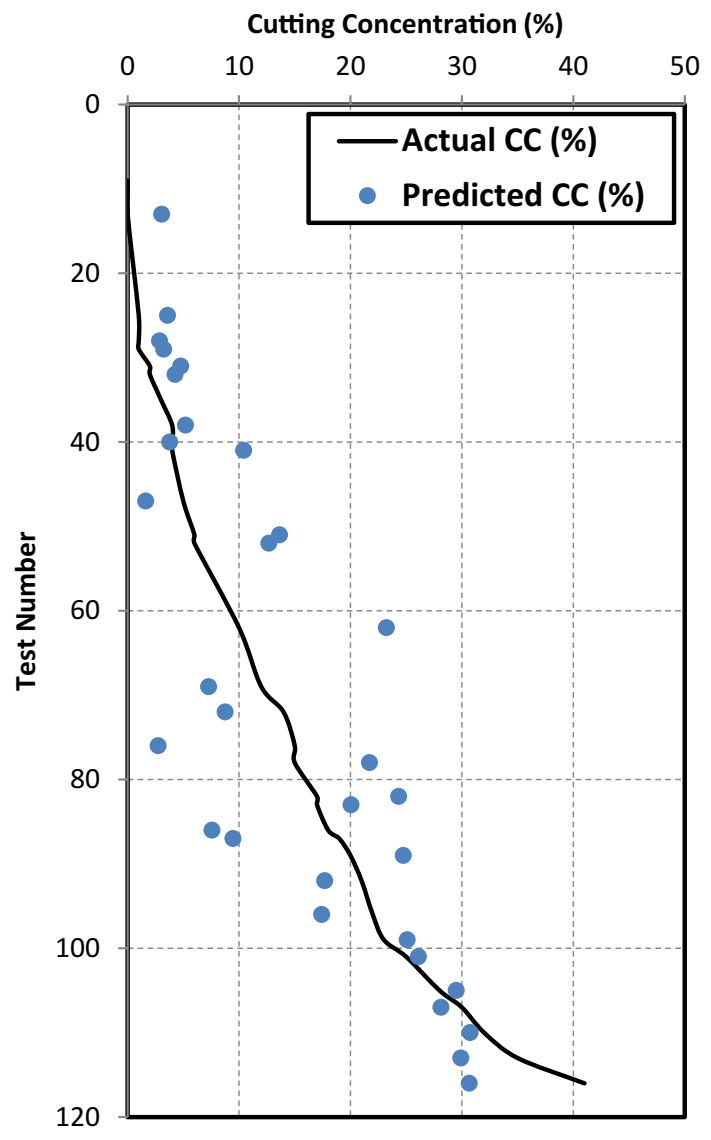

Fig. 6 Actual (experimental) and BPNN-predicted cutting concentration versus test number from network testing

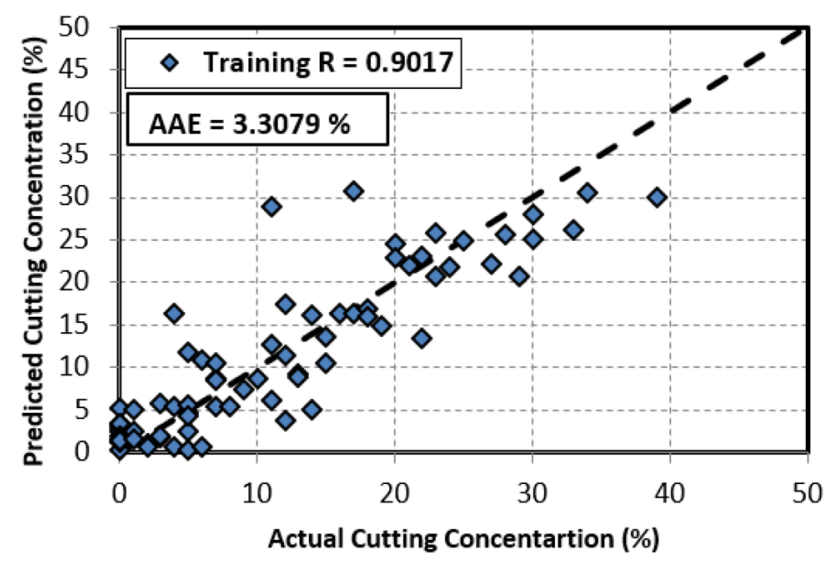

Fig. 7 BPNN-predicted versus actual (experimental) cutting concentration from network training

of the predicted and the actual cutting concentration. The training correlation coefficient and the average absolute error (AAE) in this stage are 0.956 and $2.335 \%$, respectively. The correlation coefficient for the testing stage is 0.854 with an AAE of $4.344 \%$. The training and testing

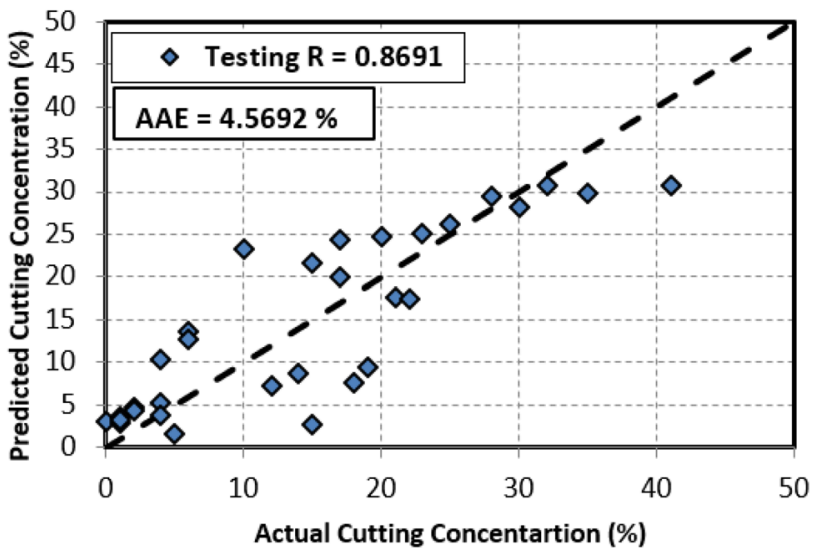

Fig. 8 BPNN-predicted versus actual (experimental) cutting concentration from network testing

Table 3 Results of estimating $\mathrm{C}_{\mathrm{C}}$ using BPNN

\begin{tabular}{lll}
\hline & $\mathrm{R}$ & $\mathrm{AAE}(\%)$ \\
\hline Training & 0.9017 & 3.3079 \\
Testing & 0.8691 & 4.5692 \\
Overall & 0.8919 & 3.6863 \\
\hline
\end{tabular}

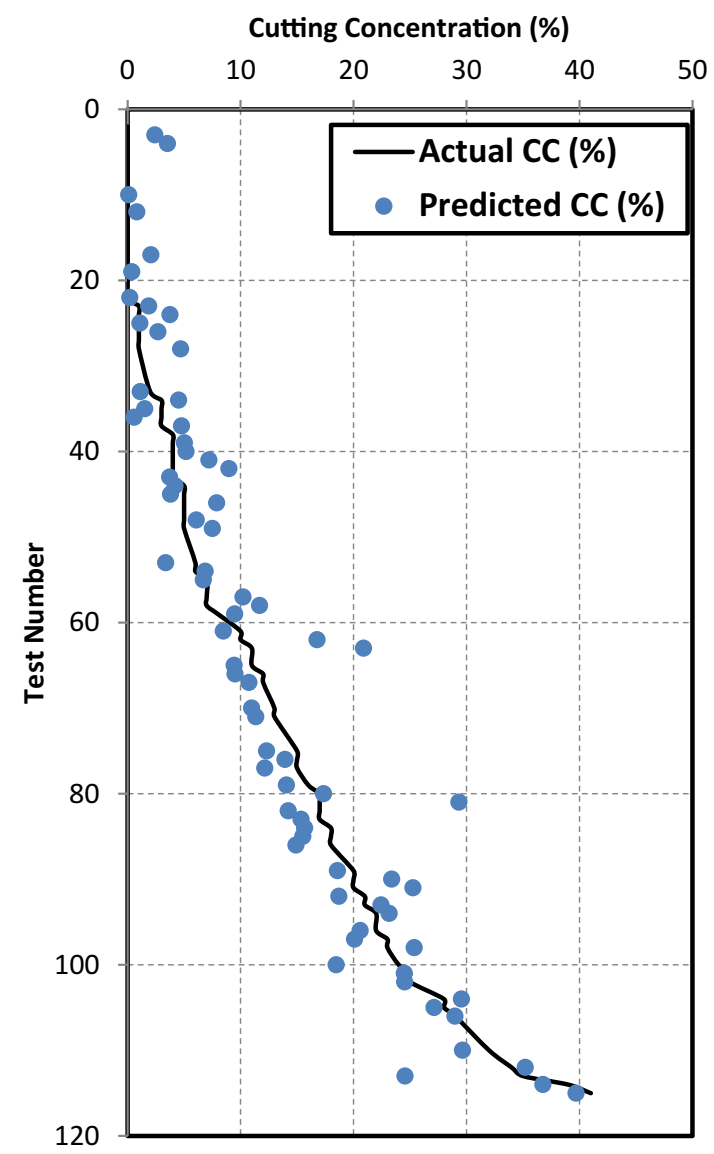

Fig. 9 Actual (experimental) and RBFN-predicted cutting concentration versus test number from training stage 


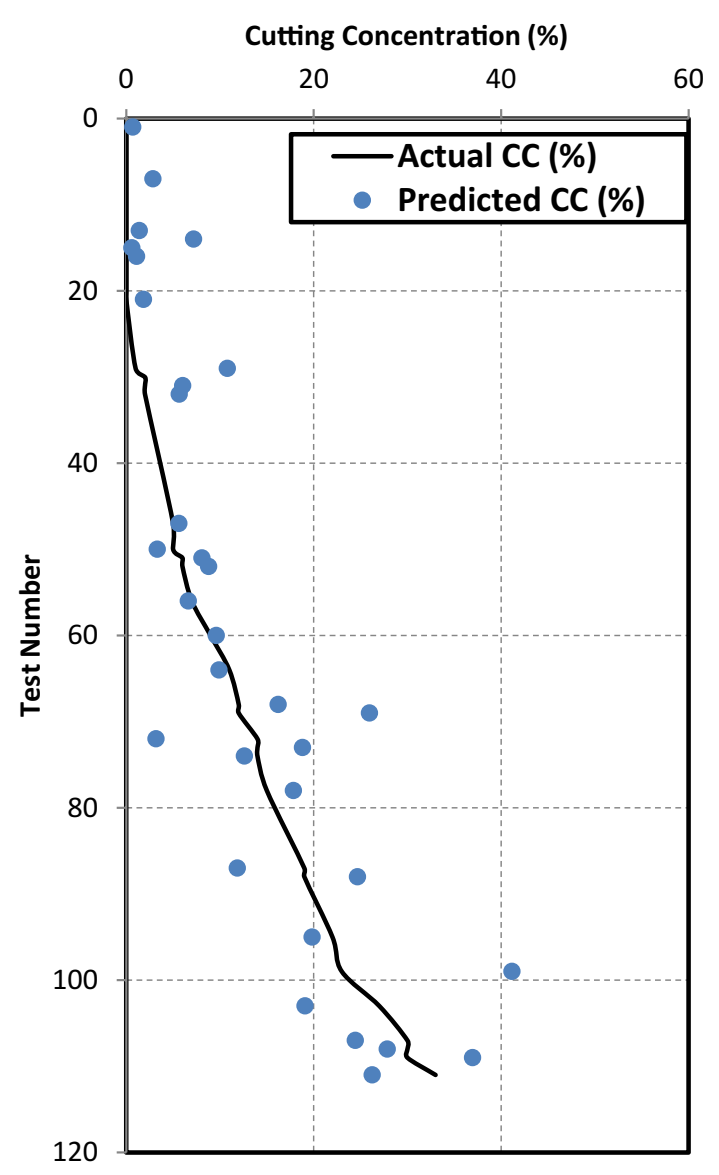

Fig. 10 Actual (experimental) and RBFN-predicted cutting concentration versus test number from testing stage

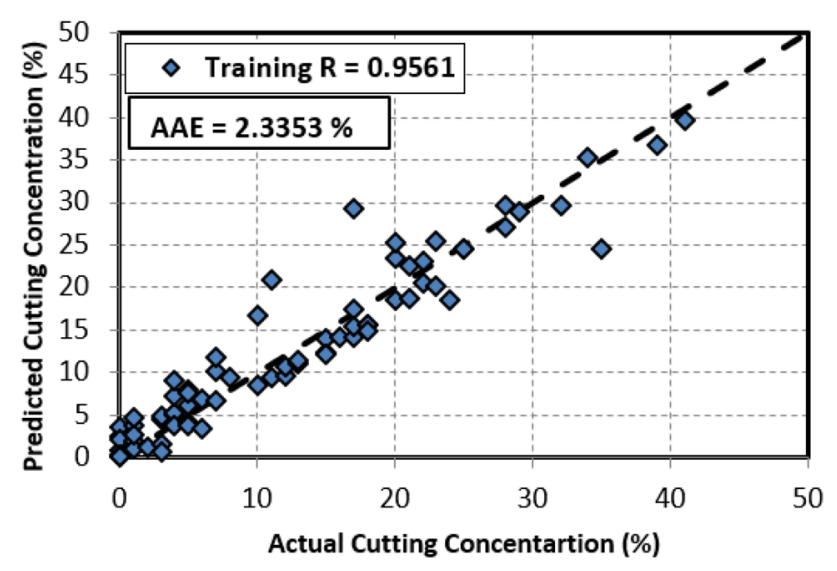

Fig. 11 RBFN-predicted versus actual (experimental) cutting concentration from training stage

results indicate that the model performance is very satisfactory. Table 4 summarizes the results obtained from implementing the RBFN technique for estimating cutting concentration. The overall correlation coefficient is 0.926

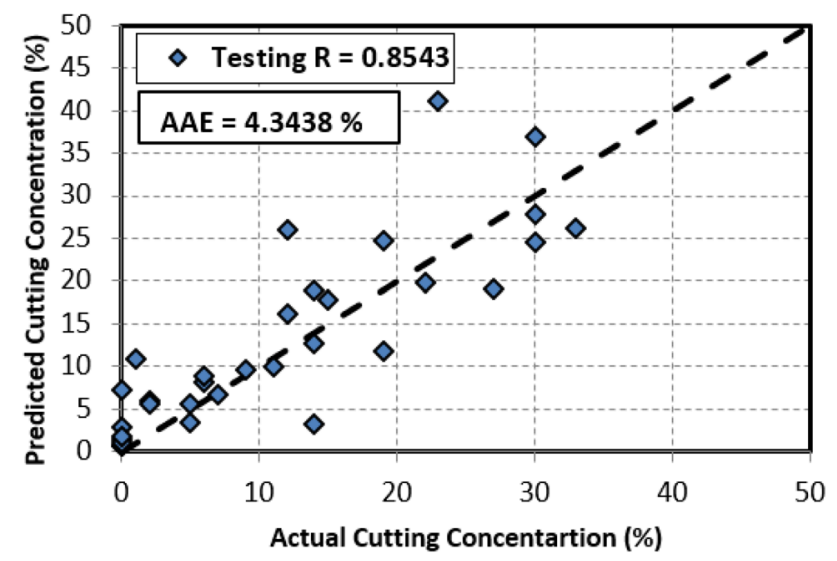

Fig. 12 RBFN-predicted versus actual (experimental) cutting concentration from testing stage

Table 4 Results of estimating $\mathrm{C}_{\mathrm{C}}$ using RBFN

\begin{tabular}{lll}
\hline & $\mathrm{R}$ & $\mathrm{AAE}(\%)$ \\
\hline Training & 0.96 & 2.335 \\
Testing & 0.85 & 4.344 \\
Overall & 0.93 & 2.938 \\
\hline
\end{tabular}

with an AAE of $2.938 \%$ which also indicate a satisfactory performance of the model.

\section{Results from SVM model}

Finally, the cutting concentration was estimated using the SVM technique. The model was trained and tested, and the best results are outlined and discussed here. Figures 13 and 14 show the plot of the actual (experimental) and predicted cutting concentration versus the test number as obtained from the training and testing stages after implementing the SVM. Figures 15 and 16 also show the regression plots for both stages between the actual and predicted data. The figures show the closeness of the predicted and the actual cutting concentration. The training correlation coefficient and the average absolute error (AAE) are 0.94 and $2.255 \%$, respectively. The correlation coefficient for the testing stage is 0.93 with an AAE of $3.644 \%$. The training and testing results indicate that the model performance is satisfactory. Table 5 summarizes the results obtained from implementing the SVM technique for estimating cutting concentration. The overall correlation coefficient is 0.93 with an AAE of $2.672 \%$ which also indicate a satisfactory performance of the model.

\section{Comparison with literature work}

Yu et al. (2007) presented an empirical correlation for cutting concentration in the wellbore. This correlation is 


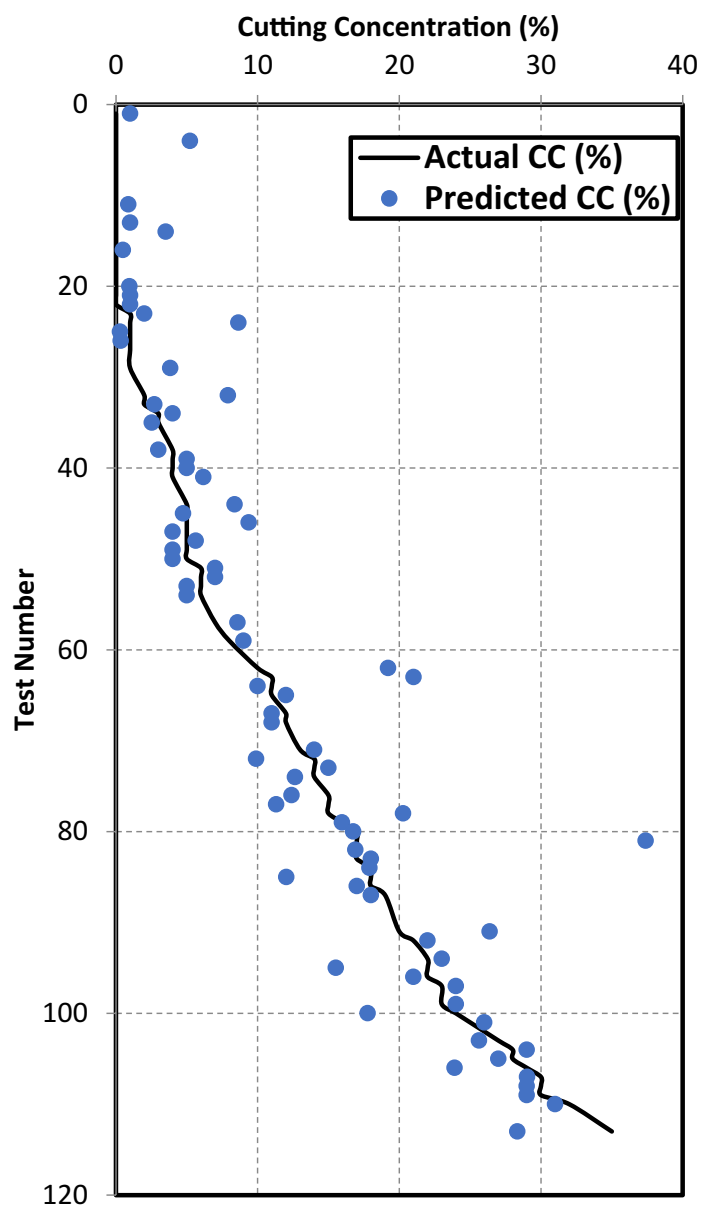

Fig. 13 Actual (experimental) and SVM-predicted cutting concentration versus test number from training stage

based on dimensional analyses and dimensionless numbers. Table 6 shows the correlation coefficient and the average absolute error obtained from their model compared to the results obtained from the AI techniques discussed above. The performance of the artificial intelligence techniques implemented in this study is much better than the empirical correlation presented in Yu et al. (2007). Figure 17 shows that the performance of the AI techniques implemented in this study is much better than the empirical correlation presented in the literature.

\section{Conclusion}

In this study, the cutting concentration in deviated and horizontal well was estimated using several AI techniques. The first technique was the BPNN which has three layers: one input layer with nine parameters, one hidden layer with nine neurons and sig-sigmoid activation function and one output layer containing the target cutting concentration. In BPNN model, the correlation coefficients between the measured

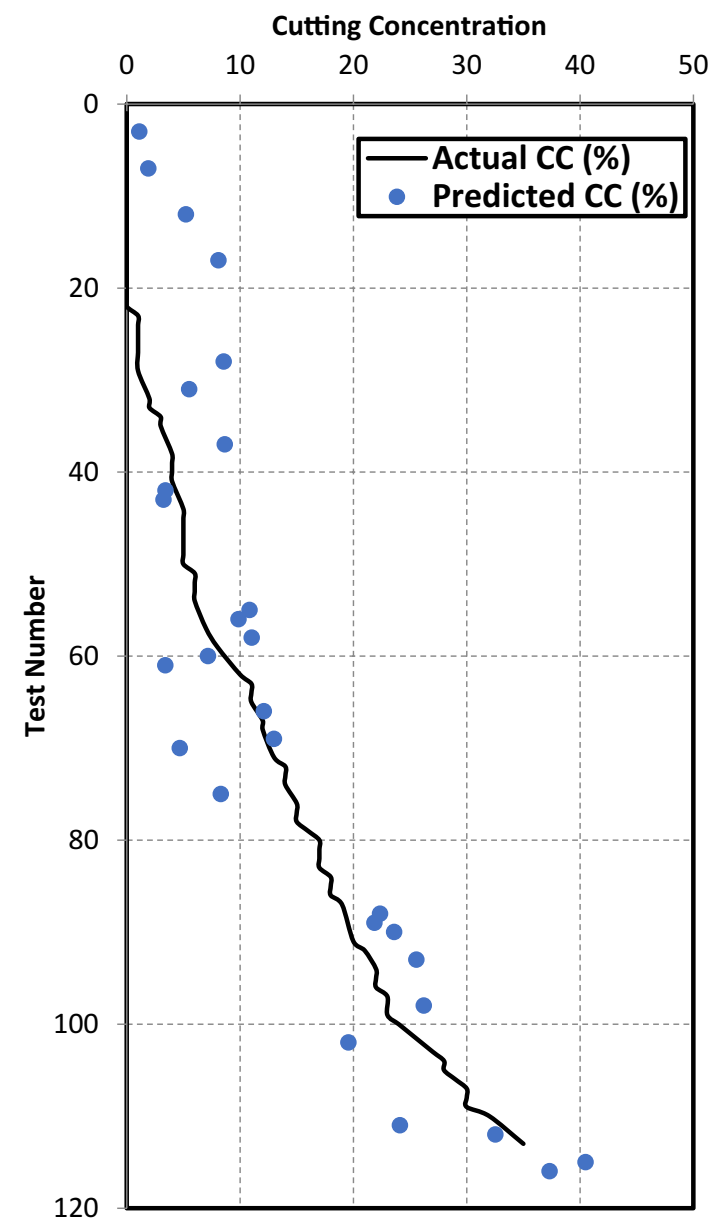

Fig. 14 Actual (experimental) and SVM-predicted cutting concentration versus test number from testing stage

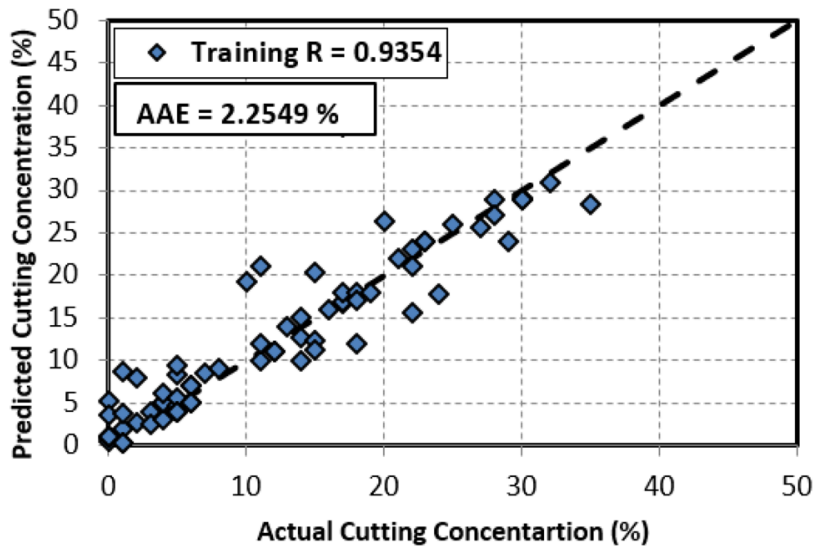

Fig. 15 SVM-predicted versus actual (experimental) cutting concentration from training stage 


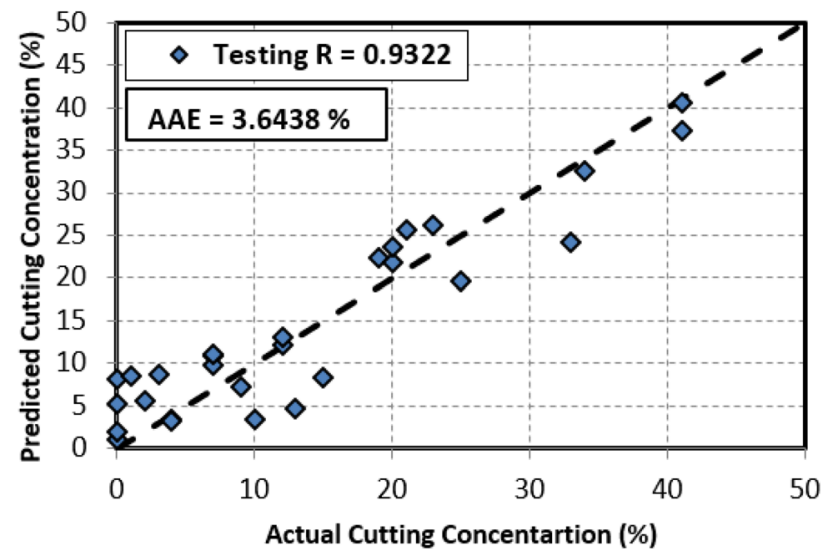

Fig. 16 SVM-predicted versus actual (experimental) cutting concentration from testing stage

Table 5 Results of estimating $\mathrm{C}_{\mathrm{C}}$ using SVM

\begin{tabular}{lll}
\hline & $\mathrm{R}$ & $\mathrm{AAE}(\%)$ \\
\hline Training & 0.94 & 2.255 \\
Testing & 0.934 & 3.644 \\
Overall & 0.934 & 2.672 \\
\hline
\end{tabular}

Table 6 Comparison of results between the empirical correlation and the AI techniques

\begin{tabular}{lllll}
\hline Model & $\begin{array}{l}\text { Yu et al. (Yu } \\
\text { et al. 2007) }\end{array}$ & BPNN & RBFN & SVM \\
\hline $\mathrm{R}$ & 0.7944 & 0.8919 & 0.9256 & 0.9344 \\
$\mathrm{R}^{2}$ & 0.6310 & 0.7955 & 0.8567 & 0.8732 \\
AAE (\%) & 5.1332 & 3.6863 & 2.9379 & 2.6716 \\
\hline
\end{tabular}

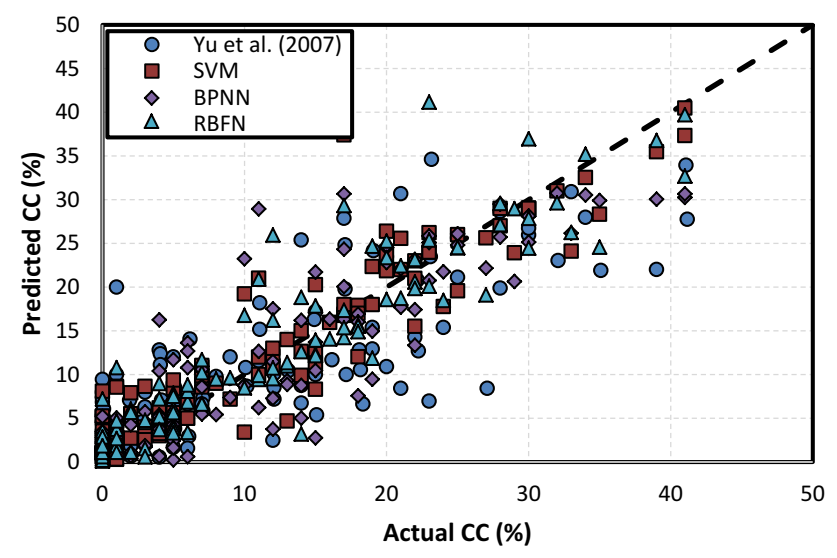

Fig. 17 Comparison of results between the empirical correlation and the AI techniques and the estimated values in the training and testing stages are 0.90 and 0.87 , respectively. The AAE for both stages are $3.308 \%$ and $4.5698 \%$, respectively. The overall correlation coefficient and AAE from this approach were 0.89 and $3.686 \%$, respectively.

Moreover, the second technique used is the RBFN. This technique uses the same inputs and output as the previous technique. The radial basis function is the activation function used in this technique. In RBFN model, the correlation coefficients between the measured and the estimated values in the training and testing stages are 0.96 and 0.856 , respectively. The AAE for both stages are $2.3356 \%$ and $4.344 \%$, respectively. The overall correlation coefficient and AAE from this approach were 0.93 and $2.938 \%$, respectively.

SVM model yielded correlation coefficients between the measured and the predicted values in the training and testing stages of 0.94 and 93, respectively. The AAE for both stages are $2.255 \%$ and $3.644 \%$, respectively. The overall correlation coefficient and AAE from this approach were 0.93 and $2.672 \%$, respectively.

Amongst all the techniques implemented in this work, SVM gave a better prediction of the results as indicated by the higher overall correlation coefficient and the least overall prediction error. However, there is no much difference in the prediction between all AI methods; it is recommended to use SVM in field application.

A comparison of the AI model results to the results obtained from published empirical model shows that the predictions of cutting concentration from the AI techniques are much better than that obtained by the published one in terms of accuracy and simplicity of application. Applying the AI technique will enable the drilling engineers to evaluate the hole cleaning in a real time with a high accuracy.

\section{Compliance with ethical standards}

Conflict of interest The authors have no conflicts of interest to declare.

Open Access This article is distributed under the terms of the Creative Commons Attribution 4.0 International License (http://creativeco mmons.org/licenses/by/4.0/), which permits unrestricted use, distribution, and reproduction in any medium, provided you give appropriate credit to the original author(s) and the source, provide a link to the Creative Commons license, and indicate if changes were made.

\section{References}

Abdulraheem A, Sabakhy E, Ahmed M, Vantala A, Raharja PD, Korvin G (2007) Estimation of permeability from wireline logs in a middle eastern carbonate reservoir using fuzzy logic. In: SPE middle east oil and gas show and conference 
Alakbari FS, Elkatatny S, Baarimah SO (2016) Prediction of bubble point pressure using artificial intelligence ai techniques. In: SPE middle east artificial lift conference and exhibition

Al-Azani K, Elkatatny S, Abdulraheem A, Mahmoud M, Ali A (2018) Prediction of cutting concentration in horizontal and deviated wells using support vector machine. In: SPE Kingdom of Saudi Arabia annual technical symposium and exhibition

Al-Marhoun MA, Nizamuddin S, Raheem AAA, Ali SS, Muhammadain AA (2012) Prediction of crude oil viscosity curve using artificial intelligence techniques. J Pet Sci Eng 86-87:111-117

Al-Shammari A, (2011) Accurate prediction of pressure drop in twophase vertical flow systems using artificial intelligence. In: SPE/ DGS Saudi Arabia section technical symposium and exhibition

Cho H, Shah SN, Osisanya SO (2001) Effects of fluid flow in a porous cuttings-bed on cuttings transport efficiency and hydraulics. In: SPE annual technical conference and exhibition

Cortes C, Vapnik V (1995) Support-vector networks. Mach Learn 20(3):273-297

Demuth H, Beale M (2002) Neural network toolbox for use with MATLAB $^{\circledR}$

Elkatatny S (2017a) Real-time prediction of rheological parameters of $\mathrm{kcl}$ water-based drilling fluid using artificial neural networks. Arab J Sci Eng 42(4):1655-1665

Elkatatny S (2017b) New approach to optimize the rate of penetration using artificial neural network. Arab J Sci Eng 43(11):6297-6304

Elkatatny S (2018) Application of artificial intelligence techniques to estimate the static poisson's ratio based on wireline log data. J Energy Resour Technol 140(7):072905

Elkatatny S, Mahmoud M (2018a) Development of new correlations for the oil formation volume factor in oil reservoirs using artificial intelligent white box technique. Petroleum 4(2):178-186

Elkatatny S, Mahmoud M (2018b) Development of a new correlation for bubble point pressure in oil reservoirs using artificial intelligent technique. Arab J Sci Eng 43(5):2491-2500

Elkatatny S, Tariq Z, Mahmoud M (2016) Real time prediction of drilling fluid rheological properties using artificial neural networks visible mathematical model (white box). J Pet Sci Eng 146:1202-1210

Elkatatny S, Mahmoud M, Tariq Z, Abdulraheem A (2017) New insights into the prediction of heterogeneous carbonate reservoir permeability from well logs using artificial intelligence network. Neural Comput Appl 30(9):2673-2683

Elkatatny S, Tariq Z, Mahmoud M, Abdulraheem A (2018a) New insights into porosity determination using artificial intelligence techniques for carbonate reservoirs. Petroleum 4(4):408-418

Elkatatny S, Tariq Z, Mahmoud M, Abdulraheem A, Mohamed I (2018b) An integrated approach for estimating static Young's modulus using artificial intelligence tools. Neural Comput Appl. https://doi.org/10.1007/s00521-018-3344-1

Elkatatny S, Tariq Z, Mahmoud M, Mohamed I, Abdulraheem A (2018c) Development of new mathematical model for compressional and shear sonic times from wireline log data using artificial intelligence neural networks (White Box). Arab J Sci Eng 43(11):6375-6389

Ford JT, Peden JM, Oyeneyin MB, Gao E, Zarrough R (1990) Experimental investigation of drilled cuttings transport in inclined boreholes. In: SPE annual technical conference and exhibition
Hussaini SM, Azar JJ (1983) Experimental study of drilled cuttings transport using common drilling muds. Soc Pet Eng J 23(01):11-20

Li J, Walker S (1999) Sensitivity analysis of hole cleaning parameters in directional wells. In: SPE/ICoTA coiled tubing roundtable

Mahmoud AAA, Elkatatny S, Mahmoud M, Abouelresh M, Abdulraheem A, Ali A (2017) Determination of the total organic carbon (TOC) based on conventional well logs using artificial neural network. Int J Coal Geol 179:72-80

Moussa T, Elkatatny S, Mahmoud M, Abdulraheem A (2018) Improved permeability correlations from well log data using artificial intelligence approaches. J Energy Resour Technol. https://doi. org/10.1115/1.4039270

Nazari T, Hareland G, Azar JJ (2010) Review of cuttings transport in directional well drilling: systematic approach. In: Paper SPE132372-MS presented at the SPE Western Regional Meeting, 27-29 May, Anaheim, California, USA

Okrajni S, Azar JJ (1986) The effects of mud rheology on annular hole cleaning in directional wells. SPE Drill Eng 1(04):297-308

Osman E-SA (2004) Artificial neural network models for identifying flow regimes and predicting liquid holdup in horizontal multiphase flow. SPE Prod Facil 19(01):33-40

Ozbayoglu EM, Miska SZ, Reed T, Takach N (2002) Analysis of bed height in horizontal and highly-inclined wellbores by using artificial neuraletworks. In: SPE international thermal operations and heavy oil symposium and international horizontal well technology conference

Pigott RJS (1941) Mud flow in drilling. In: Paper API-41-091 presented at the Drilling and Production Practice, 1 January, New York

Ravi K, Hemphill T (2006) Pipe rotation and hole cleaning in eccentric annulus. In: IADC/SPE drilling conference

Rooki R, Rakhshkhorshid M (2017) Cuttings transport modeling in underbalanced oil drilling operation using radial basis neural network. Egypt J. Pet 26(2):541-546

Rooki R, Doulati Ardejani F, Moradzadeh A (2014) Hole cleaning prediction in foam drilling using artificial neural network and multiple linear regression. Geomaterials 04(01):47-53

Sanchez RA, Azar JJ, Bassal AA, Martins AL (1999) Effect of drillpipe rotation on hole cleaning during directional-well drilling. SPE J 4(02):101-108

Tomren PH, Iyoho AW, Azar JJ (1986) Experimental study of cuttings transport in directional wells. SPE Drill Eng 1(01):43-56

Williams CE, Bruce GH (1951) Carrying Capacity of Drilling Muds. J Pet Technol 3(04):111-120

Yu M, Takach NE, Nakamura DR, Shariff MM (2007) An experimental study of hole cleaning under simulated downhole conditions. In: SPE annual technical conference and exhibition

Zhao H, Ru Z, Zhao X, Meng Y (2010) Application of support vector machine in slope engineering

Publisher's Note Springer Nature remains neutral with regard to jurisdictional claims in published maps and institutional affiliations. 